\title{
PÉREZ, T. G. (Org.). Identidades docentes: la renovación del oficio de enseñar. Valência: Tirant Humanidades Edita: Tirand Lo Blanch, 2017. 233 p.
}

Teaching identities: the renewal of the teaching profession

\author{
Eloísa Helena MELLO'
}

Identidades docentes: la renovación del oficio de enseñar (2017) se trata de uma relevante obra reflexiva sobre a formação docente nas diversas épocas e contextos. $\mathrm{O}$ texto apresenta uma coletânea de textos acerca da formação e identidade docentes, tema amplamente discutido na atualidade nos diversos congressos e eventos científicos. Sob a organização de Tereza González Pérez, este livro instiga no leitor a curiosidade sobre a identidade docente em diversos períodos explicitados, bem como nos desafia a refletir sobre as transformaçóes ocorridas nos planos de ensino da formação docente e peculiaridades próprias de cada nação.

Compreender os elementos constitutivos da formaçáo docente e os eixos norteadores da prática do professor fomenta a discussão: por que alguns conteúdos contemplam o plano de ensino dos cursos de formação de professores e não outros? Quais critérios são imprescindíveis para formar um profissional do magistério de excelência? $\mathrm{O}$ que de fato diferencia na formação do professor para que este se constitua um profissional consciente de sua responsabilidade na formação humana e cidadã?

São essas algumas das inquietaçóes que os diversos autores que compóem a obra oportunizam ao leitor de modo a revelar o que está por detrás da formação docente. Nesse contexto, somos convidados a compreender essas especificidades e, com a autonomia científica que o texto traz, estabelecer relaçóes entre a explanação didática e histórica dos capítulos, e o efetivo comprometimento com a formação do pedagogo nas diversas naçóes.

$\mathrm{Na}$ introdução do livro, Tereza González Pérez justifica a escolha do tema formação docente, sendo essa uma questão prioritária nas discussóes teóricas e em encontros científicos. Defende que a educação é reflexo das intenções políticas e que a formação dos professores não escapa desse processo. Salienta que a variedade de programas, as sucessivas leis, as reformas políticas influenciam a regulação

1 Pós Doutoranda pela PUCPR, Doutora e Mestra em Políticas Públicas em Educação pela Universidade Tuiuti do Paraná. Orcid: https://orcid.org/0000-0003-2649-6350. Lattes: http://lattes.cnpq. br/9550550998400403. E-mail: e.lo.h@hotmail.com 
política da formação do professor e, mesmo sem ser valorizado, o orgulho em exercer sua profissão se faz presente em muitas biografias.

Desde última década do século $\mathrm{XX}$, a formação docente é um tema muito controverso, mas de interesse comum, pois é o elemento chave para o desenvolvimento dos seres humanos. O preparo desse professor com qualidade é o desafio. Na Europa, a exemplo da Espanha, defende-se a formação universitária, melhorando o nível de preparação tanto dos conteúdos teóricos como da prática docente, enquanto nos estados ibero-americanos prevalece um caráter mais profissionalizante. No âmbito internacional, o trabalho docente varia de um país a outro, dependendo do nível de seu desenvolvimento.

Este livro analisa a formação inicial do magistério. Em seus capítulos, estão incluídos aspectos gerais da formação nos diversos contextos internacionais. A obra foi escrita por professores conceituados que analisam a história do magistério do século XX e discutem a complexidade de ser professor assim como sua própria identidade profissional.

A respectiva obra é recomendada para alunos, pesquisadores, professores e estudiosos da formação do magistério. Nos trabalhos expostos na obra é possível analisar os diversos modelos de formação inicial do professor nos diversos níveis. As reformas educativas interferem na formação de professores, e por vezes a formação do futuro professor torna-se uma etapa curta, limitada e com deficiências.

A obra recorre à visão das tendências formativas na capacitação do magistério nos países ibero-americanos e seus problemas, debatendo diversas questóes situadas nos marcos histórico, político e educativo contemporâneos. A referida obra oferece uma visão geral da formação e da ação do professor em diferentes momentos do século XX, configurando a trajetória formativa e o perfil dos professores no Brasil, no Chile, no México e na Espanha. A organizadora da referida obra seguiu a ordem cronológica dos oito capítulos que a compóem.

No primeiro capítulo, Maestras Parvularias chilenas a principios del siglo XX, a autora Estela Socías Muñoz relata a educação pré-escolar no Chile. Enfatiza em sua análise a criação do jardim de infância a nível público em Santiago como uma educaçáo primária obrigatória. Destaca que, por muito tempo, as professoras eram consideradas como uma extensão da maternidade, com o objetivo de atender a aspectos morais e a valores no que diz respeito à educação não formal das crianças, inibindo sua profissionalização. Dessa forma, a criação das escolas de párvulos tornava-se uma opção para especializar esse atendimento, utilizando-se de jogos e partindo das necessidades da criança. Esse modelo escolar teve influência da tendência montessoriana, em 1912, e expandiu-se também pela procura das mães que necessitavam deixar seus filhos na escola. O livro destaca que, atualmente no Chile, a educação parvulária tem cobertura também do setor privado, com financiamento e projetos reconhecidos mundialmente. 
O texto Revolución Mexicana, reforma educativa y resistencia, de Yolanda Padilla Rangel, aborda o papel das professoras na educação mexicana antes e depois da revolução mexicana. Analisa a reforma educativa do presidente Carranza, que visualiza na educação um instrumento eficaz para melhorar a cultura e as condiçóes sócio-econômicas do seu povo, além de legitimar sua ideologia. Carranza defende que a educação mexicana deveria ser laica, gratuita e obrigatória, mas de forma autoritária, e propóe uma instrução nacionalista e popular. Nesse processo, Carranza encontrou resistência das professoras, principalmente Vicenta Trujillo, diretora da Escola Normal de Professoras, que foi a primeira mulher que praticou o magistério e, após vários conflitos, assumiu o posto de Diretora de Educação, destacando-se como primeira mulher a assumir essa função.

No texto Misiones culturales y maestros rurales: México na década de 1920, Marco A. Calderón Mólgora mostra como se organizaram as missóes culturais e seu vínculo com a formação dos professores que atuavam no espaço do campo com os indígenas. Destaca o problema do analfabetismo em índice elevado e o despreparo dos docentes nesse ofício. Remover a indiferença ao analfabetismo, mobilizou as primeiras missóes, que buscavam, no ensino do campo, levar conhecimentos gerais desde noçóes de higiene até a formação cultural. Os professores passavam por cursos diversos visando aprimoramento profissional, mas com ênfase na industrialização do campo, justificando a intencionalidade das missóes.

O texto La formación de maestros em España a lo largo del siglo XX, de Juana Maria Rodrigues Gomez, analisa a formação inicial do magistério do século XX e discorre sobre as influências da Escola Nova, as mudanças de práticas de ensino com a proposta curricular de objetivos específicos e os critérios de avaliação, ressaltando a dicotomia entre as matérias culturais e profissionais. Nesse período, foram fundados os Institutos Gerais e Técnicos e os planos de estudo passaram a responder aos interesses políticos, enfatizando a formação técnica na educação. Acentua-se nessa perspectiva as didáticas nos planos de ensino. $\mathrm{O}$ critério para ingresso na escola normal restringiu-se à idade de dezesseis anos e à boa conduta. O movimento da Escola Nova impulsionou a reorganização das Escolas Normais. A tarefa docente passou a enfatizar o alcance de objetivos e a formas de avaliá-los, baseados nos quatro pilares da educação: aprender a ser, a fazer, a conviver e a conhecer, planejando a ação e refletindo sobre esta.

$\mathrm{O}$ texto La identidad de las professoras primarias em el estado de ParanálBrasil de 1930 a 1960, de autoria de Aricle Vechia, explica o processo histórico da feminilização do magistério. Este estudo revela a identidade do professor no sul do Brasil, na cidade de Curitiba, capital do Estado do Paraná, entre 1930 e 1960. Em sua análise, cabe esclarecer que as estudantes da escola normal pertenciam a classe média-alta da sociedade e possuíam hábitos refinados com conduta exemplar e 
considera que a baixa remuneração foi responsável pelo esvaziamento do gênero masculino nesse ofício. Nas décadas de 20 e 30, considerava-se que uma boa professora tinha bondade de coração e pureza de alma, e a ênfase na moral e na conduta eram requisitos para assumir a função, ficando os conhecimentos técnicos em segundo plano. Com o advento do Estado Novo a missão das professoras era nacionalizar a população. A partir da década de 40 a educação tomou novos rumos cuja finalidade era a transformação social, preparando as crianças para o convívio em sociedade e preparando-as para o mercado de trabalho. O professor é reconhecido dessa forma como profissional do magistério.

No texto Nuevas perspectivas: La evolución del perfil de Magisterio em la sociedade española del último tercio del siglo XX, a autora Maria Jesús Vera Cazorla analisa as transformaçóes da formação de professores no final do século XX, período de transição da ditadura franquista para a democracia. Nesse período, buscava-se superar o atraso em que se encontrava o país. Cabe esclarecer que a Lei Geral da Educação, de 1970, e as matérias do Plano de Estudo de 1971, que defendem a educação para todos os cidadâos com maior uniformidade e currículo abrangendo matérias relacionadas à pedagogia e à psicologia. $\mathrm{O}$ autor relata que os professores eram majoritariamente de classe média-baixa. Com a Lei de 1970, destaca-se a necessidade de renovação pedagógica com práticas mais contextualizadas e de interesse dos alunos. Freinet e Paulo Freire subsidiavam essa discussão. Esse movimento de renovação, ocorrido entre 1970 e 1983, teve impacto na formação dos professores de modo a ajustar o ensino ministrado às necessidades e expectativas da sociedade espanhola.

$\mathrm{O}$ texto Identidades docentes y programas de estúdio para el magistério en la etapa democrática, de autoria de Teresa González Pérez, explica o processo de renovação da formação do magistério na Espanha entre 1970 e 1990, transição do franquismo para a democracia. Cabe esclarecer que a Lei Geral da Educação de 1970, cuja tarefa era levar, pela educação, à melhoria do nível cultural do povo, introduzindo inovaçóes na educação, descentralizando sua gestão, antes comandada pela igreja católica. Nessas mudanças, enfatiza-se a organização curricular em ciclos, avançando na universalização da educação, expansão e melhorias técnicas e de materiais. Cabe esclarecer que o autor desse capítulo sobre os novos desafios da Lei Orgânica de 1990, a qual projeta uma reforma educativa melhorando a qualidade da formação inicial do professor e a qualidade da educação. Segundo Pérez a educação não pode ficar à margem dos avanços sociais e tecnológicos e que a identidade docente é resultado de um processo biográfico e social, dependente da formação inicial e das condições de exercício da prática profissional.

O último texto, Regulación social y producción de subjetividades en cursos de formación de profesores: flexibilidade, actualización, autodisciplina, competencia, 
motivación, do autor Claudemir de Quadros, estuda a trajetória do Centro Universitário Franciscano localizado no sul do Brasil (1903), vinculado a uma instituição holandesa, responsável pela formação de docentes e destinado à formação da elite. Cabe esclarecer sobre o currículo da instituição com intenção de formaçáo religiosa e as divergências com o proposto pelo Manifesto de 1932, que defendem a gratuidade do ensino. Nessa análise, destaca-se a transição das Faculdades Franciscanas em Centro Universitário Franciscano e a reforma educacional para os cursos de graduação proposta pelo Ministério da Educação no Brasil. Quadros esclarece sobre o controle do governo, interesses de organismos internacionais nos resultados educacionais, diretrizes curriculares baseadas na produtividade docente e eficiência na sua formaçáo, a fim de modernizar as instituiçóes sob a perspectiva dos interesses políticos e econômicos.

A leitura desta obra contempla diversos olhares e perspectivas, possibilita repensar como se efetivou a formação de professores ao longo do século XX em análises detalhadas dessa formação e da construção de sua identidade a nível internacional. Nos diversos contextos geográficos, pode-se perceber algumas similaridades na formação do professor, considerando que esta se constitui conforme o que se espera na sociedade em determinado período. Ao mesmo tempo, Quadros perpassa especificidades características de cada país, contextualizando o momento histórico e sua influência no direcionamento das políticas explicitadas nos planos de ensino.

A referida obra é um convite ao leitor para desfrutar de uma análise minuciosa, didática, reflexiva referente à formaçáo docente em diversos contextos e para perceber a intencionalidade dessa formação na prática profissional. $\mathrm{O}$ legado dessas especificidades expostas na obra permitem que o leitor invista em estudos sobre o tema, construindo conhecimento científico e considerando que muito há para se revelar no que se refere à identidade docente e sua formaçáo.

\section{Referências}

PÉREZ, T. G. (Org.). Identidades docentes: la renovación del oficio de enseñar. Valência: Tirant Humanidades Edita: Tirand Lo Blanch, 2017. 233 p. 